\title{
Interest to consider re-challenging by cetuximab and platinum containing regimen in recurrent Head and Neck Cancer
}

\author{
Christian Borel ${ }^{1,7}$, Olivier Regnier-Gavier ${ }^{2}$, Hélène Carinato ${ }^{1}$, Sébastien Guihard ${ }^{3,7}$, \\ Delphine Antoni ${ }^{3,9}$, Martin Demarchi ${ }^{1}$, Florian Sirlin ${ }^{4}$, Delphine Exinger ${ }^{2}$, Emilie \\ Petit-Jean $^{2}$, Alicia Thiery ${ }^{5}$, Guy Bronner ${ }^{6}$, Philippe Schultz ${ }^{6,8}$, Henri Flesch ${ }^{6}$, \\ Véronique Frasie ${ }^{4}$, Danielle Prébay ${ }^{2}$, Thierry Petit ${ }^{1}$, Alain C. Jung7,10, Mickael \\ Burgy $^{1}$ and Pierre Coliat ${ }^{2,7,10}$ \\ ${ }^{1}$ Medical Oncology Department, Centre Paul Strauss, Strasbourg, France \\ ${ }^{2}$ Pharmacy Department, Centre Paul Strauss, Strasbourg, France \\ ${ }^{3}$ Radiotherapy Department, Centre Paul Strauss, Strasbourg, France \\ ${ }^{4}$ Supportive Care Department, Centre Paul Strauss, Strasbourg, France \\ ${ }^{5}$ Biostatistics Department, Centre Paul Strauss, Strasbourg, France \\ ${ }^{6}$ ENT Specialist, Strasbourg, France \\ 7Université de Strasbourg, Inserm IRFAC UMR_S1113, group «STREINTH », Strasbourg, France \\ ${ }^{8}$ Department of Otolaryngology Head and Neck Surgery, Hôpitaux Universitaires de Strasbourg, Strasbourg, France \\ ${ }^{9}$ Radiobiology Laboratory, Centre Paul Strauss, Université de Strasbourg, Strasbourg, France \\ ${ }^{10}$ Tumor biology Laboratory, Centre Paul Strauss, Université de Strasbourg, Strasbourg, France \\ Correspondence to: Pierre Coliat, email: pcoliat@strasbourg.unicancer.fr \\ Keywords: HNSCC; EXTREME; re-challenge; platinum free Interval \\ Received: November 27, $2018 \quad$ Accepted: December 13,2018 Published: December 25, 2018
}

Copyright: Borel et al. This is an open-access article distributed under the terms of the Creative Commons Attribution License 3.0 (CC BY 3.0), which permits unrestricted use, distribution, and reproduction in any medium, provided the original author and source are credited.

\section{ABSTRACT}

Background: The EXTREME protocol is the standard of care for recurrent or metastatic head and neck squamous-cell carcinoma (R/M HNSCC) in first line. Beyond the first-line except immunotherapy, poor efficacy was reported by second-line chemotherapy. Re-challenge strategies based on a repetition of the first line with platinum and cetuximab regimens might have been an option to consider.

Methods: We performed a retrospective study in order to assess the efficacy of the cetuximab plus platinum doublet-based chemotherapy regimen in patients with R/M HNSCC progressing after at least 3 months of cetuximab maintenance (EXTREME protocol). We complete a retrospective review of all medical records from $R / M$ HNSCC patients treated after 16 weeks with the EXTREME regimen and treated with a rechallenge strategy between January 2010 and December 2014 in our institution (Centre Paul Strauss, Strasbourg, France).

Results: 33 patients were identified. The re-challenged strategy provided an ORR in $\mathbf{3 3 . 3} \%$ of cases and a DCR of $\mathbf{6 9 . 6 \%}$ of cases. The median OS and PFS observed from the second line were $\mathbf{1 1 . 2}$ months and 6.5 months for the subset re-challenged by EXTREME or PCC regimens respectively. The response rate between patients with a platin free interval within 3 and 6 months and greater than 6 months were equal. Drugs dose intensity were better with the PCC protocol than the EXTREME regimen used as a rechallenge.

Conclusions: This study suggest re-challenging strategy by these regimens could be considered beyond the first line as an option when the platin free interval is greater than 3 months. 


\section{INTRODUCTION}

The survival outcome of patients with a locoregional or metastatic recurrences $(\mathrm{R} / \mathrm{M})$ of head and neck squamous carcinoma (HNSCC) is dismal. In 2008, the addition of cetuximab to conventional platinum $/ 5 \mathrm{FU}$ chemotherapy (EXTREME regimen) has improved their overall survival [1]. These results have supported the EXTREME protocol approval as the standard of care for $\mathrm{R} / \mathrm{M}$ HNSCC in first line.

Beyond the first-line when a progressive disease occurred, limited therapeutic options are available. Poor efficacy was reported by second-line chemotherapy $[2,3]$. Of interest, immunotherapy including nivolumab or pembrolizumab, have provided encouraging results supporting their recent approval in 2nd line for R/M HNSCC $[4,5]$. On the other hand, strategies based on a repetition of the first line with platinum and cetuximab regimens might have been an option to consider. Herein, we report a series of patients with R/M HNSCC, rechallenged in second line by a platinum and cetuximabcontaining regimen.

\section{RESULTS}

A total of 33 patients were re-challenged from 122 patients treated with the EXTREME protocol as the first line setting. Among them 18 and 15 were treated by PCC and EXTREME regimens respectively.

\section{Population characteristics}

A total of 122 patients were treated in first line by EXTREME regimen. The OS and PFS observed for the 122 patients treated in first line setting were in line with the Vermorken study [1] (Data not shown). Among them, 33 patients eligible in the present study were re-challenged and their characteristics are summarized in Table 1. The majority were males $(75.7 \%)$, the median age was 57 years. Tumour sites were predominantly oropharynx $(42.4 \%)$ and larynx $(21.1 \%)$. The OMS score was two for $36.4 \%(n=12)$ of patients. Roughly half of patients had metastatic tumours (52\%). All patients received an EXTREME protocol in first line and the carboplatin was the preferred drug $(87.9 \%)$ compared with the cisplatin (12.1\%). The first line with the EXTREME protocol achieved 22 OR and 11 SD. The PFI was within 3 and 6 months and longer than 6 months in 20 and 13 cases respectively.

\section{Primary objective}

The re-challenged strategy provided an ORR in $33.3 \%$ [ $95 \%$ CI $17.2-49.4 \%$ ] of cases and a DCR of $69.6 \%$ [95\% CI 53.9-85.3\%] of cases. A total, of 2 patients $(6 \%)$ were not evaluable for response, 11 achieved a PR, 12 a SD and 8 a PD.
Among the 22 patients who experienced a response in first line, a second response in second line with EXTREME or PCC was reached in 8 patients $(36.3 \%)$. Among the 11 patients with a SD in first line, an OR was achieved for 3 patients in second line with PCC (Table 2).

\section{Secondary objectives}

The survival, the median OS and PFS observed from the second line were 11.2 months $(95 \%$ CI, 8.6-13.8) and 6.5 months (95\% CI, 3.1-9.9) for the subset re-challenged by EXTREME or PCC regimens respectively (Figure 1).

The response rate between patients with a PFI within 3 and 6 months and greater than 6 months are statistically similar with an ORR of $30 \%(6 / 20)$ and $38 \%(5 / 13)$ and a DCR of $70 \%(14 / 20)$ and $69 \%(9 / 13)$ respectively (Table 3$)$.

Almost 20 weeks of treatment was achieved for cetuximab and paclitaxel, 15 weeks for carboplatin and 12 weeks for 5-fluorouracile. The median dose intensity for cetuximab, paclitaxel and 5-fluorouracile is between $80 \%$ and $90 \%$ of the planned dose per week (Table 4 ).

Major toxicity of these protocols were neutropenia, anaemia and cutaneous toxicity. Side effects are in line with the drugs and protocols used and described in literature (Table 5).

\section{DISCUSSION}

In second-line treatment of R/M HNSCC, before the approval of immune checkpoint inhibitors, no standard has been defined: best supportive care or second line chemotherapies including monotherapy with methotrexate, paclitaxel, docetaxel or cetuximab were usually proposed $[2,6,7]$. In our study, among the 86 patients who could receive a second line chemotherapy, 53 were treated, according to these recommendations, with a single drug or a bi-therapy. The 33 others patients with a disease control of at least, 3 months after the 6 cycles of first line EXTREME chemotherapy where treated by a chemotherapy containing platinum and cetuximab with $5 \mathrm{FU}$ or paclitaxel. Interestingly, the observed efficacy results were quite similar to those observed in first line in terms of ORR, DCR and PFS.

The re-challenge strategy is an old concept and abundant example are present in the literature addressing several cancers [8]. The efficacy reported was supported by the tumour resistance concept. In the review of Kucynski et al., in 2013, several types of resistance were mentioned such as non-heritable drug resistance or a drug holiday-mediated tumour re-sensitization. The disease progression after the completion of a therapy was not necessarily related to drug resistance but only reflect the partial and temporary efficacy of the agent. The interval between the progressive disease occurrence might be an indicator of the possible tumour resistance regarding the previously given drugs. In R/M HNSCC 


\begin{tabular}{|c|c|}
\hline & $N=33(\%)$ \\
\hline \multicolumn{2}{|l|}{ Gender } \\
\hline Male & $25(76)$ \\
\hline Female & $8(24)$ \\
\hline \multicolumn{2}{|l|}{ Age } \\
\hline Median & 57 \\
\hline$<65$ years & $29(88)$ \\
\hline$\geq 65$ years & $4(12)$ \\
\hline \multicolumn{2}{|l|}{ Score OMS/Karnofsky } \\
\hline $0-1$ & $21(64)$ \\
\hline 2 & $12(36)$ \\
\hline \multicolumn{2}{|c|}{ Primary tumor localization } \\
\hline Oropharynx & $14(42)$ \\
\hline Hypopharynx & $6(18)$ \\
\hline Larynx & $7(21)$ \\
\hline Oral cavity & $6(18)$ \\
\hline \multicolumn{2}{|l|}{ Tumor extension } \\
\hline Recurrent only & $16(48)$ \\
\hline Metastatic disease & $17(52)$ \\
\hline \multicolumn{2}{|l|}{ Histologic type } \\
\hline Well differentiated & $8(24)$ \\
\hline Moderately differentiated & $11(33)$ \\
\hline Poorly differentiated & $6(18)$ \\
\hline Missing & $8(24)$ \\
\hline \multicolumn{2}{|l|}{ 1st Line extreme } \\
\hline Cisplatin & $4(12)$ \\
\hline Carboplatin & $29(88)$ \\
\hline Response rate (1st line) & $N=33$ \\
\hline Complete Response & $2(6)$ \\
\hline Partial Response & $20(61)$ \\
\hline Stable Disease & $11(33)$ \\
\hline
\end{tabular}

Table 2: ORR according to treatment (Extreme or PCC)

\begin{tabular}{|c|c|c|c|c|c|}
\hline \multicolumn{2}{|c|}{ NB PTS } & PR & \multirow{2}{*}{ SD } & ND & \multirow{2}{*}{ Total } \\
\hline \multirow{2}{*}{ Extreme } & $3(20 \%)$ & 7 & & 15 \\
\cline { 2 - 3 } & \multicolumn{2}{|c|}{$\mathrm{DCR}=66 \%$} & 4 & 1 & 18 \\
\hline \multirow{2}{*}{ PCC } & $8(44 \%)$ & 5 & 8 & 2 & 33 \\
\hline
\end{tabular}

a cytotoxic holiday over the cetuximab maintenance might be considered and our cohort appears qualified as a re-challenge approach.
In our present cohort, the sensitivity to platinum salts might be considered beyond an interval free of progression of 3 months. In the literature, it has been 

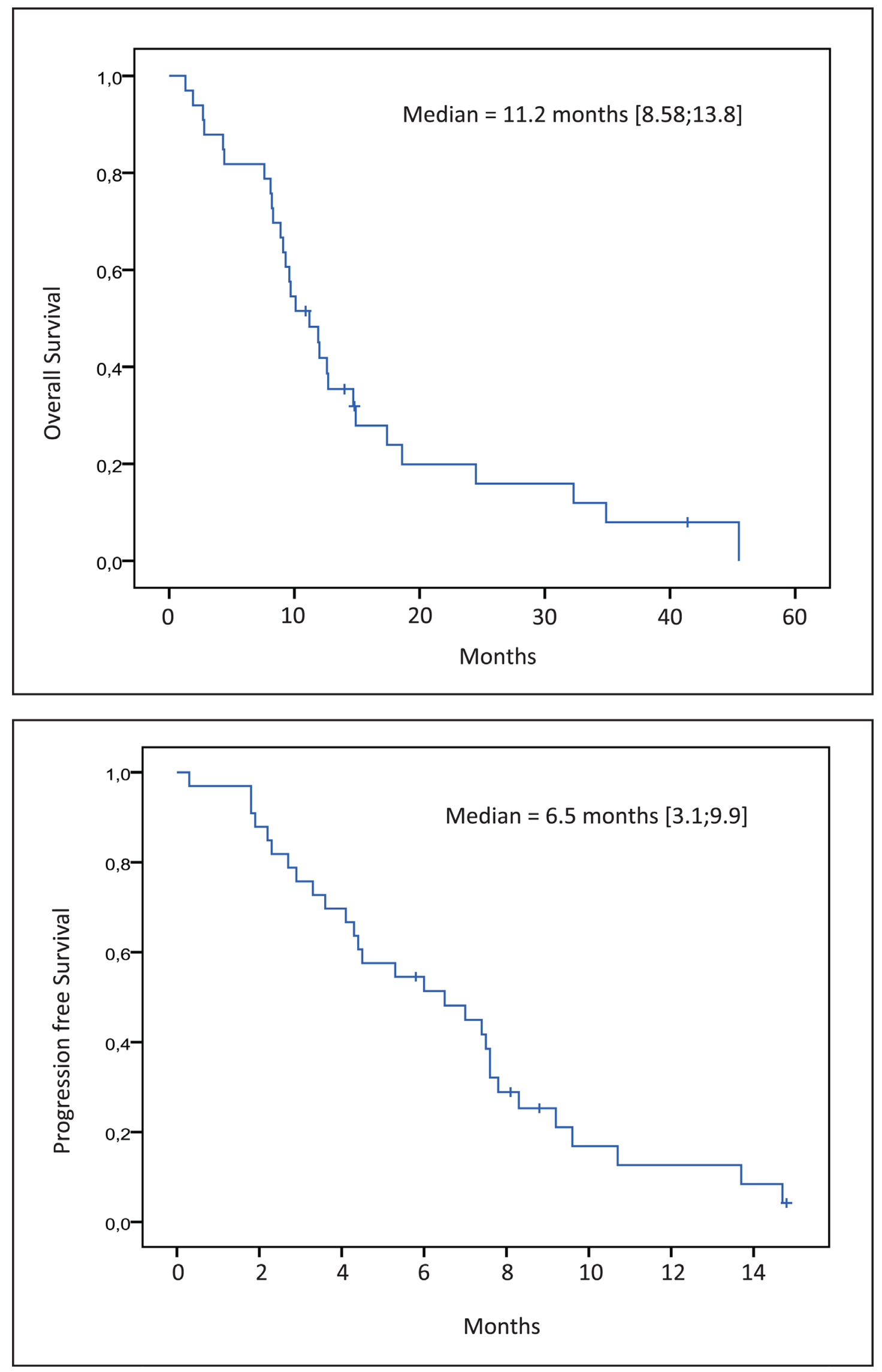

Figure 1: Kaplan-Meier estimate of overall survival and progression free survival. 
Table 3: Overall response rate according to PFI (Platinum free interval)

\begin{tabular}{|c|c|c|c|c|}
\hline NB PTS & PR & SD & PD & NE \\
\hline \multirow{2}{*}{$3 \mathrm{Mo}<\mathrm{PFI}<6 \mathrm{Mo}$} & $6(30 \%)^{1}$ & 8 & \multirow{2}{*}{4} & \multirow{2}{*}{2} \\
\hline & \multicolumn{2}{|c|}{$\mathrm{DCR}=70 \%{ }^{2}$} & & \\
\hline \multirow{2}{*}{ PFI $>6$ Mois } & $5(38 \%)^{1}$ & 4 & \multirow{2}{*}{4} & \multirow{2}{*}{0} \\
\hline & \multicolumn{2}{|c|}{$\mathrm{DCR}=69 \%{ }^{2}$} & & \\
\hline \multirow{2}{*}{ Total } & $11(33 \%)$ & 12 & \multirow{2}{*}{8} & \multirow{2}{*}{2} \\
\hline & \multicolumn{2}{|c|}{$\mathrm{DCR}=69 \%$} & & \\
\hline
\end{tabular}

1,2: No statistical difference was observed for PR (Khi2 test: $p$-value $=1$, CI 95:(0.19 5.7) OR $=1.02$ ) and for DCR (Fischer exact test: $p$-value $=0.6894 \mathrm{CI} 95(0.210 .7) \mathrm{OR}=1.53)$ between the 2 subsets $(3 \mathrm{Mo}<\mathrm{PFI}<6 \mathrm{Mo}$ and PFI $>6 \mathrm{Mo})$

Table 4: Dose intensity

\begin{tabular}{|c|c|c|c|}
\hline \multicolumn{2}{|c}{ Median total dose (mg/m $)$} & $\begin{array}{c}\text { Median dose intensity } \\
\left(\mathbf{m g} / \mathbf{m}^{2} / \text { week) }\right.\end{array}$ & $\begin{array}{c}\text { Median total dose/median dose } \\
\text { intensity (week) }\end{array}$ \\
\hline Cetuximab & 4016 & 211 & 19,0 \\
\hline 5-Fluorouracile & 14550 & 1210 & 12 \\
\hline Paclitaxel & 1166 & 54 & 21.6 \\
\hline & Median Total Dose (mg) & Median Dose Intensity (mg/week) & $\begin{array}{c}\text { Median total dose/median dose } \\
\text { intensity (week) }\end{array}$ \\
\hline Carboplatin & 2450 & 165 & 14.8 \\
\hline
\end{tabular}

Table 5: Toxicity

\begin{tabular}{lcc}
\hline Toxicity & All grades (\%) & Grades 3-4 (\%) \\
\hline Neutropenia & $22(64,0)$ & $8(24,0)$ \\
Dysphagia & $9(27)$ & $7(21)$ \\
Cutaneous & $25(76)$ & $4(12)$ \\
Anemia & $25(76)$ & $3(9)$ \\
Thrombocytopenia & $17(52)$ & $2(6)$ \\
Neuropathy & $10(30)$ & $2(6)$ \\
Asthenia & $9(27)$ & $2(6)$ \\
Mucositis & $5(15)$ & $1(3)$ \\
Nausea, vomiting & $4(12)$ & $1(3)$ \\
Febrile neutropenia & $1(3)$ & $1(3)$ \\
Diarrhea & $1(3)$ & $1(3)$ \\
Thoracic pain & $3(9)$ & - \\
Infection & $4(12)$ & - \\
Hypersensitivity & - & - \\
\hline
\end{tabular}

widely accepted that patients progressing within 6 months after the last platinum dose had a refractory disease. This is supported by 5 phases II studies performed in $\mathrm{R} / \mathrm{M}$ patients who had progressed during or after platinum first line chemotherapy. Four of them were performed with a combination of cetuximab and a platinum salt which was reintroduced after the last 1 st line chemotherapy administration [9-11]. Response rates reported in these clinical trials were ranged from $6 \%$ to $10 \%$, and median survival were between 4.3 to 6.1 months. Interestingly, in the same early clinical recurrence, with a cetuximab monotherapy, a response rate of $13 \%$ and a 5,9 months median survival was reported [11]. Therefore, efficacy according to a PFI within 3 to 6 months and beyond 6 months was not investigated. In our study, similar results were observed between the two subsets with variable PFI. 


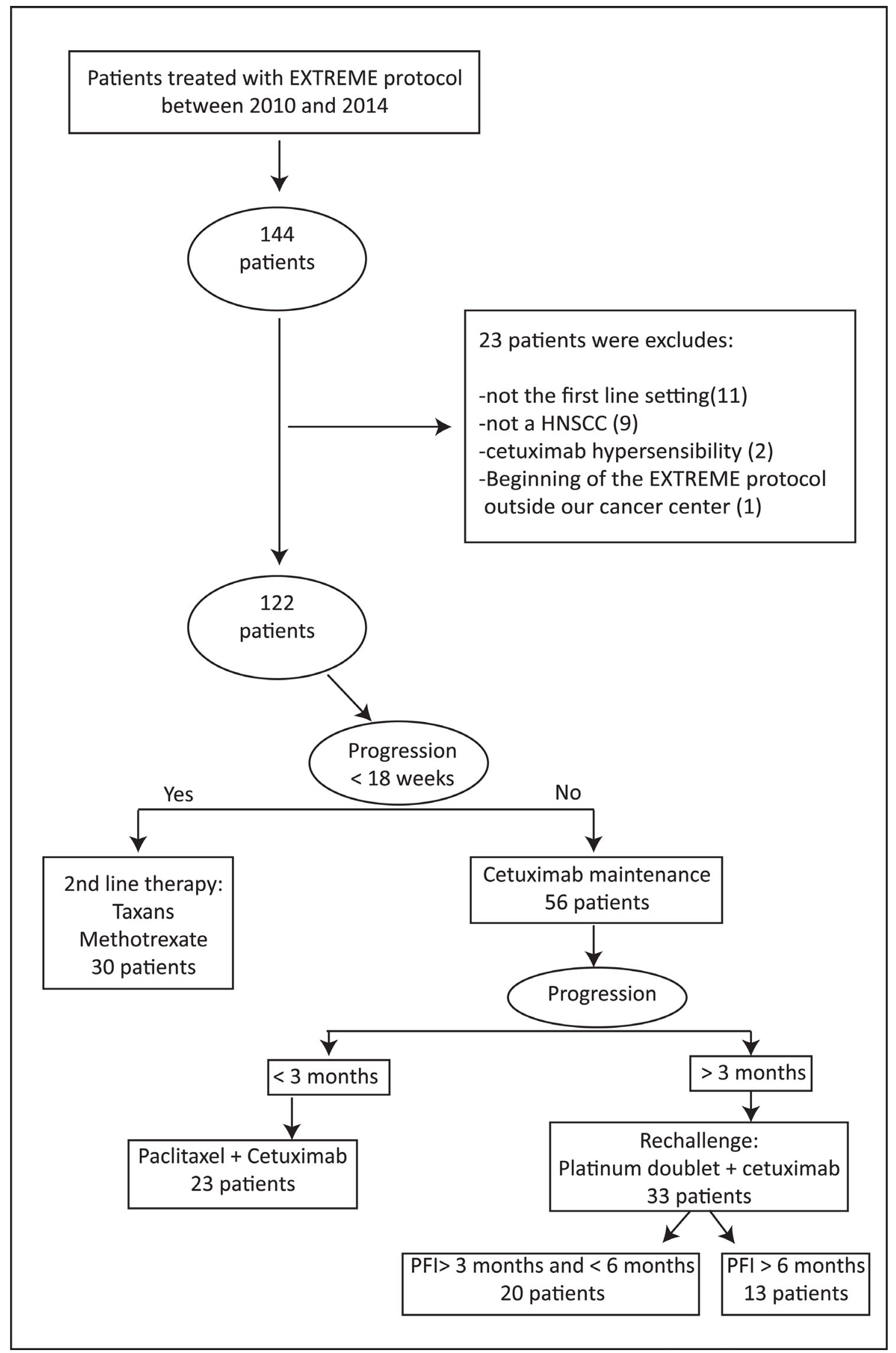

Figure 2: Selection process. 
This point suggested that patients who progressed sooner than 6 months from the last platinum dose might not be refractory to the platinum salts in this setting.

\section{MATERIALS AND METHODS}

\section{Patient's selection}

From the computerized chemotherapy prescribing software database (AS400), all patients in the Paul Strauss Cancer Center from January 2010 and December 2014 treated in first line setting by the EXTREME regimen chemotherapy were identified. From the retrospective analysis of patient's medical chart, treatment characteristics and outcomes were collected in compliance with the European data protection laws (RGPD). Patients with synchronous or second primary cancer, as well as patients with incomplete follow-up data were excluded. The common accepted strategy in our institution was to re-challenge with platinum and cetuximab regimen a patient with the occurrence of a progressive disease while they received cetuximab maintenance. The progression should occur beyond the third month after the completion of platinum from the EXTREME regimen. The selection process is explained in Figure 2. All follow-up data were updated until April 2016.

\section{Treatment}

All eligible patients were treated in second line with the EXTREME protocol described by Vermorken et al. [1] or with the PCC protocol reported by Kies et al. [12]. EXTREME regimen included: cisplatin $\left(100 \mathrm{mg} / \mathrm{m}^{2}\right)$ or carboplatin (AUC 5) on day one (D1), 5-FU (1000 mg/m² continuous infusion D1-D4) and cetuximab (loading dose (LD) of $400 \mathrm{mg} / \mathrm{m}^{2}$ followed by $250 \mathrm{mg} / \mathrm{m}^{2}$ infusions (D1, D8, D15)). Administration of chemotherapy was repeated every 3 weeks (D1 = D22) with a maximum of 6-cycles, followed by maintenance administration of cetuximab given weekly $\left(250 \mathrm{mg} / \mathrm{m}^{2}\right)$ or bi-weekly $\left(500 \mathrm{mg} / \mathrm{m}^{2}\right)$. PCC regimen included: Weekly Paclitaxel $80 \mathrm{mg} / \mathrm{m}^{2}+$ Carboplatin AUC2 + Cetuximab $250 \mathrm{mg} / \mathrm{m}^{2}\left(\mathrm{LD}=400 \mathrm{mg} / \mathrm{m}^{2}\right)$ on D1 with a maximum of 16 courses, followed by maintenance administration of cetuximab given weekly or bi-weekly.

\section{End-points}

This study was aimed to analyse the efficacy of rechallenge strategy in a 2 nd line setting, in recurrent or metastatic Head and Neck Cancer with cetuximab plus platinum regimen in real life population.

The primary end-point was to evaluate the response rate in patients re-challenged. The response rate is composed with 2 criteria: The Overall response Rate (ORR) (Complete Response (CR) + Partial Response $(\mathrm{PR}))$ and The Disease Control Rate (DCR) (ORR + Stable
Disease (SD)). Responses were defined according to the RECIST criteria.

Secondary end-points were second line Overall Survival (OS: time from the onset of 2nd line chemotherapy to death or to last follow-up) and 2nd line Progression Free Survival (PFS: time from the onset of 2nd line chemotherapy to death or progression).

The relationship between the platinum free interval (PFI) (within 3 and 6 months or longer than 6 months) and endpoints was investigated.

Toxicity and dose intensity data were also collected.

\section{Statistical analysis}

The statistics were mainly descriptive. OS and PFS were estimated with the Kaplan-Meier method. The response rate (OOR and DCR) comparison between the PFI subsets (3-6 months and $>6$ months) was performed by Khi2 test or Fischer exact test. Statistical calculations were performed with $\operatorname{SPSS}^{\circledR}$ V.22 $\left(\right.$ IBM $\left.^{\circledR}\right)$.

\section{CONCLUSIONS}

In conclusion, at progression, treatment-containing platinum based chemotherapy and cetuximab (EXTREME or PCC chemotherapy) provided interesting results. Rechallenge by these regimens could be considered beyond the first line as an option when the PFI is greater than 3 months.

\section{CONFLICTS OF INTEREST}

$\mathrm{CB}$ has received honorariums for consulting by Merck, Astra-Zeneca, BMS, and has been Advisory board consultant for Merck and BMS. Other authors have no personal or institutional financial interest in any of the drugs, material, or devices described in this paper.

\section{REFERENCES}

1. Vermorken JB, Mesia R, Rivera F, Remenar E, Kawecki A, Rottey S, Erfan J, Zabolotnyy D, Kienzer HR, Cupissol D, Peyrade F, Benasso M, Vynnychenko I, et al. Platinumbased chemotherapy plus cetuximab in head and neck cancer. N Engl J Med. 2008; 359:1116-27. https://doi. org/10.1056/NEJMoa0802656.

2. Machiels JP, Haddad RI, Fayette J, Licitra LF, Tahara M, Vermorken JB, Clement PM, Gauler T, Cupissol D, Grau JJ, Guigay J, Caponigro F, de Castro G Jr, et al, and LUX-H\&N 1 investigators. Afatinib versus methotrexate as second-line treatment in patients with recurrent or metastatic squamouscell carcinoma of the head and neck progressing on or after platinum-based therapy (LUX-Head \& Neck 1): an openlabel, randomised phase 3 trial. Lancet Oncol. 2015; 16:58394. https://doi.org/10.1016/S1470-2045(15)70124-5. 
3. Kushwaha VS, Gupta S, Husain N, Khan H, Negi MP, Jamal N, Ghatak A. Gefitinib, Methotrexate and Methotrexate plus 5-Fluorouracil as palliative treatment in recurrent head and neck squamous cell carcinoma. Cancer Biol Ther. 2015; 16:346-51. https://doi.org/10.4161/15384047.2014.961881.

4. Ferris RL, Blumenschein G Jr, Fayette J, Guigay J, Colevas AD, Licitra L, Harrington K, Kasper S, Vokes EE, Even C, Worden F, Saba NF, Iglesias Docampo LC, et al. Nivolumab for Recurrent Squamous-Cell Carcinoma of the Head and Neck. N Engl J Med. 2016; 375:1856-67. https://doi. org/10.1056/NEJMoa1602252.

5. Cohen EE, Machiels JP, Harrington KJ, Burtness B, Shin SW, Gause CK, Swift AM, Brown H, Perrone AM, Cheng JD, Swaby RF, Le Tourneau C. KEYNOTE-040: A phase III randomized trial of pembrolizumab (MK-3475) versus standard treatment in patients with recurrent or metastatic head and neck cancer. J Clin Oncol. 2015; 33:TPS6084-6084.

6. Vermorken JB, Trigo J, Hitt R, Koralewski P, Diaz-Rubio E, Rolland F, Knecht R, Amellal N, Schueler A, Baselga J. Open-label, uncontrolled, multicenter phase II study to evaluate the efficacy and toxicity of cetuximab as a single agent in patients with recurrent and/or metastatic squamous cell carcinoma of the head and neck who failed to respond to platinum-based therapy. J Clin Oncol. 2007; 25:2171-77. https://doi.org/10.1200/JCO.2006.06.7447.

7. Bowles DW, Kochenderfer M, Cohn A, Sideris L, Nguyen N, Cline-Burkhardt V, Schnadig I, Choi M, Nabell L, Chaudhry A, Ruxer R, Ucar A, Hausman D, et al. A Randomized, Phase II Trial of Cetuximab With or Without PX-866, an Irreversible Oral Phosphatidylinositol 3-Kinase Inhibitor, in Patients With Metastatic Colorectal Carcinoma. Clin Colorectal Cancer. 2016; 15:337-344.e2. https://doi. org/10.1016/j.clcc.2016.03.004.
8. Kuczynski EA, Sargent DJ, Grothey A, Kerbel RS. Drug rechallenge and treatment beyond progressionimplications for drug resistance. Nat Rev Clin Oncol. 2013; 10:571-87. https://doi.org/10.1038/nrclinonc.2013.158.

9. Baselga J, Trigo JM, Bourhis J, Tortochaux J, Cortés-Funes H, Hitt R, Gascón P, Amellal N, Harstrick A, Eckardt A. Phase II multicenter study of the antiepidermal growth factor receptor monoclonal antibody cetuximab in combination with platinum-based chemotherapy in patients with platinum-refractory metastatic and/or recurrent squamous cell carcinoma of the head and neck. J Clin Oncol. 2005; 23:5568-77. https://doi.org/10.1200/JCO.2005.07.119.

10. Herbst RS, Arquette M, Shin DM, Dicke K, Vokes EE, Azarnia N, Hong WK, Kies MS. Phase II multicenter study of the epidermal growth factor receptor antibody cetuximab and cisplatin for recurrent and refractory squamous cell carcinoma of the head and neck. J Clin Oncol. 2005; 23:5578-87. https://doi.org/10.1200/JCO.2005.07.120.

11. Vermorken JB, Herbst RS, Leon X, Amellal N, Baselga $J$. Overview of the efficacy of cetuximab in recurrent and/ or metastatic squamous cell carcinoma of the head and neck in patients who previously failed platinum-based therapies. Cancer. 2008; 112:2710-19. https://doi.org/10.1002/cncr.23442.

12. Kies MS, Holsinger FC, Lee JJ, William WN Jr, Glisson BS, Lin HY, Lewin JS, Ginsberg LE, Gillaspy KA, Massarelli E, Byers L, Lippman SM, Hong WK, et al. Induction chemotherapy and cetuximab for locally advanced squamous cell carcinoma of the head and neck: results from a phase II prospective trial. J Clin Oncol. 2010; 28:8-14. https://doi.org/10.1200/JCO.2009.23.0425. 